\title{
Metropolitan Governance in Europe
}

\author{
Karsten Zimmermann ${ }^{1}$ Panagiotis Getimis ${ }^{2}$
}

Different processes of rescaling in the EU countries have multi-faceted impact on the governance and planning of metropolitan areas. There is a variety of institutional forms, planning practices and episodes manifested and experimented recently in the metropolitan regions of Europe, while there is a gap of knowledge about these, both in the scholarly debate and in the world of practitioners. It is characteristic for the academic debate that although several books on metropolitan governance have been produced during the last years, there is no systematic comparison of factors that influence the institutional form of metropolitan governance, the success factors and the performance of metropolitan governance and especially the role of metropolitan planning.
In the call for paper for this special issue of Raumforschung und Raumordnung I Spatial Research and Planning, we asked the authors to fill this gap. The authors were asked to describe the recent trends in their countries and refer to issues such as the history of metropolitan policies and governance, national urban policies and the structure and performance of metropolitan governance. As a result, the contributions to this special issue all deal with trends that are observable all over Europe: decentralization, re-scaling, the effect of austerity policies and the modernization of the state in times of crisis.

We thank all contributors to this special issue and the editors of the journal for their patience and help.

Prof. Dr. Karsten Zimmermann

karsten.zimmermann@tu-dortmund.de

Prof. Dr. Panagiotis Getimis

getimisp@gmail.com

1 Fachgebiet Europäische Planungskulturen, Technische Universität Dortmund, August-Schmidt-Straße 6, 44227 Dortmund, Germany

2 Institut für Politikwissenschaft, Technische Universität Darmstadt, Dolivostraße 15, 64293 Darmstadt, Germany 